\title{
Nudging hair shedding by antidandruff shampoos. A comparison of $1 \%$ ketoconazole, $1 \%$ piroctone olamine and $1 \%$ zinc pyrithione formulations
}

\author{
C. Piérard-Franchimont, V. Goffin, F. Henry, I. Uhoda, C. Braham and G. E. Piérard \\ Department of Dermatopathology, University Medical Center Sart Tilman, B-4000 Liège, Belgium
}

Received 29 March 2002, Accepted 22 May 2002

Keywords: dandruff, hair shedding, ketoconazole, piroctone olamine, zinc pyrithione

\section{Synopsis}

Hair shedding and hair thinning have been reported to be affected by dandruff and seborrhoeic dermatitis. The present study was conducted in 150 men presenting with telogen effluvium related to androgenic alopecia associated with dandruff. They were randomly allocated to three groups receiving each one of the three shampoos in the market containing either $1 \%$ ketoconazole (KTZ), $1 \%$ piroctone olamine (PTO) or $1 \%$ zinc pyrithione (ZPT). Shampoos had to be used 2-3 times a week for 6 months. Hair shedding during shampoo was evaluated semiquantitatively. Hair density on the vertex was evaluated on photographs using a Dermaphot. Trichograms were used for determining the anagen hair percentage and the mean proximal hair shaft diameter using computerized image analysis. The sebum excretion rate (SER, $\mu \mathrm{g} \mathrm{cm}^{-2} \mathrm{~h}^{-1}$ ) was also measured using a Sebumeter ${ }^{\mathbb{R}}$.

The three treatments cleared pruritus and dandruff rapidly. At end point, hair density was unchanged, although hair shedding was decreased (KTZ: $-17.3 \%$, PTO: $-16.5 \%$, ZPT: $-10.1 \%$ ) and the anagen hair percentage was increased (KTZ: $4.9 \%$, PTO: $7.9 \%$, ZPT: $6.8 \%$ ). The effect on the mean hair shaft diameter was contrasted between the three groups of volunteers (KTZ: 5.4\%, PTO: 7.7\%, ZPT: $-2.2 \%)$. In conclusion, telogen effluvium was controlled by KTZ, PTO and ZPTshampoos at $1 \%$ concentration. In addition, KTZ and PTO increased the mean hair shaft thickness while discretely decreasing the sebum output at the skin surface.

Correspondence: Gerald Piérard. E-mail: gerald.pierard@ ulg.ac.be

\section{Résumé}

Tant la perte que la raréfaction des cheveux ont été rapportés être affectées par l'état pelliculaire et la dermite séborrhéique. Cette étude a été conduite chez 150 hommes souffrant d'un effluvium télogène en relation avec une alopécie androgénique associée à un état pelliculaire. Ils furent inclus de manière alléatoire dans trois groupes recevant un parmi trois shampooings contenant $1 \%$ de kétoconazole (KTZ), $1 \%$ de piroctone olamine (PTO) ou $1 \%$ de pyrithione de zinc (ZPT). Les shampooings étaient destinés à être utilisés 2 à 3 fois par semaine pendant 6 mois. La quantité de cheveux perdus au cours du shampooing a été évaluée semiquantitativement. La densité pilaire sur le vertex a été mesurée sur des photographies prises à l'aide d'un Dermaphot ${ }^{\circledR}$. Des trichogrammes ont servi à létablissement du pourcentage de cheveux en phase anagène et pour mesurer le diamètre de la partie proximale des cheveux en utilisant l'analyse informatisée d'images. Le débit d'excrétion sébacée (DES, $\mu \mathrm{g} \mathrm{cm}^{-2} \mathrm{~h}^{-1}$ ) fut également mesuré à l'aide d'un Sebumeter ${ }^{\circledR}$.

Les trois traitements ont rapidement fait disparâ̂tre le prurit et les pellicules. A l'issue de la phase d'observation, la densité pilaire était inchangée bien que la perte de cheveux soit diminuée (KTZ: -17.3\%, PTO: $-16.5 \%$, ZPT: $-10.1 \%)$ et que le pourcentage des cheveux en phase anagène soit accru (KTZ: 4.9\%, PTO: 7.9\%, ZPT: $6.8 \%$ ). L'effet sur le diamètre moyen des cheveux était différent selon les groupes de volontaires (KET: 5.4\%, PTO: 7.7\%, ZPT: $-2.2 \%$ ). En conclusion, l'effluvium télogène a été amoindri par les shampooings renfermant $1 \%$ de KTZ, PTO ou ZPT. De plus, le KTZ et le PTO ont accru le calibre 
maoyen des cheveux alors qu'ils diminuaient discrètement le débit sébacé à la surface de la peau.

\section{Introduction}

Since the hair cycle and its turning points have been largely identified [1-4], molecular mechanisms controlling hair chronobiology are progressively disclosed $[5,6]$. The complex interactions between hair growth hair, shedding, sebaceous gland functions, angiogenesis [7,8], microinflammation and its counterpart immuno-suppression [9-15], and neuroendocrine and hormonal influences [16-18] are far from being clarified. The environmental impact including solar irradiation [19] and commensal microorganisms $[11,13]$ cannot be neglected either. All these factors may affect the natural evolution of hair shedding and modulate the progression of alopecia [20].

There is an overwhelming body of evidence that dandruff and seborrhoeic dermatitis are two related clinical manifestations of one common dermatological disorder [21-30]. Dandruff is primarily a scaling condition without any clinical evidence for inflammation, although subclinical microinflammation is present [25]. Seborrhoeic dermatitis is the clinically recognized inflammatory counter-part of the same disorder. Erythema is always present, and the inflammatory lymphoid infiltrate is more pronounced [24]. Cosmetic or over-the-counter remedies are used for dandruff, and patients may easily turn to prescriptiontype medicine for the inflammatory presentation.

Although it is generally agreed that the lipophilic yeasts of the genus Malassezia are a key contributor in the pathogenesis of dandruff and seborrhoeic dermatitis, these skin conditions are not regarded as an infection [31-35]. It is the mere over-colonization of the scalp and other areas of the body rich in sebaceous glands by this yeast that causes an inconspicuous-to-moderate inflammatory reaction, resulting in variable degrees in erythema and disturbed desquamation.

Usually, signs and symptoms of dandruff focus in the first place on scaling and itching. However, it is clear that several other clinical features are present in conjunction with this disorder. These include seborrhoea, telogen effluvium, a reducing proportion in anagen hair and thin hair shaft diameter [30]. It is not clear if the relationship between these latter phenomena and seborrhoeic dermatitis is causal or circumstantial.

In view of the frequent association between seborrhoea, telogen effluvium, thin hair, androgenic alopecia and the clinical manifestations of dandruff and seborrhoeic dermatitis on the scalp, it was decided to evaluate the effects of ketoconazole (KTZ), piroctone olamine (PTO) and zinc pyrithione (ZPT) on these parameters.

\section{Materials and methods}

The trial protocol was approved by the Ethics Committee of the University of Liège and was performed in accordance with the declaration of Helsinki and its subsequent revisions. Subjects gave their written consent to participate in the study after having been informed about its nature, risks and benefits. The study ran from autumn to spring the year after. A total of 150 men aged from 18 to 65 years presenting with mild-to-moderate dandruff, telogen effluvium related to androgenic alopecia (Hamilton grade III) of the vertex were enrolled. They were randomly assigned to shampoo 2-3 times per week for 6 months with $1 \% \mathrm{KTZ}$ shampoo, $1 \%$ PTO shampoo or $1 \% \mathrm{ZPT}$ shampoo. Each group was composed of 50 panelists. Baseline data as well as those gathered after 4 and 6 months of treatment, were collected for all subjects. These included the determination of the sebum excretion rate (SER), the percentage of anagen hair, the mean proximal hair shaft diameter $(\mu \mathrm{m})$, the hair density $\left(\mathrm{N} \mathrm{cm}^{-2}\right)$, and the hair shedding during shampoo. No side-effect was recorded but 19 subjects were lost to follow-up between the 4th and 6th month of treatment (six in the KTZ group, six in the PTO group and seven in the ZPT group).

SER was measured $\left(\mu \mathrm{g} \mathrm{cm}^{-2} \mathrm{~h}^{-1}\right)$ at the hairline, one hour after the skin had been wiped with $70 \%$ ethanol. A computerized Sebumeter SM 810 (C + K Electronic, Cologne, Germany) was used as previously described [36,37].

Hair density $\left(\mathrm{n} \mathrm{cm}^{-2}\right)$ was assessed on photographs of the central part of the vertex using a Dermaphot ${ }^{\circledR}$ Heine. By using a 3-point midline and facial coordinate system, precise relocation of the same site was achieved for the assessments gathered after the baseline assessment. Samples of more than 100 individual hair were obtained from the same vertex area. Trichograms yielded the proportion of hair in the anagen phase. Computerized image analysis (MOP Videoplan Kontron, Eiching, Germany) was used on the same hair samples to measure the mean diameter of the proximal part of the hair shafts.

Hair shedding was assessed using semiquantitative counts of the hair collected during the last shampoo, the day before the subject's visit to the 
laboratory for evaluation. Hair were collected in a transparent envelope which was coded and blinded for further assessment. These envelopes were compared to a series of reference envelopes kept at the laboratory. Each of these reference envelopes contained multiples of five hair. Without knowledge of the subject's treatment, the number of shed hair in the subject's envelope was matched to the reference standard.

The carry-on forward method was applied to the intent-to-treat assessments. Absolute values were considered. Means and SD were calculated for each parameter at each evaluation time. Before and after treatment, values were compared using the paired two-tailed Student's $t$-test. Intergroup differences were searched using variance analysis. Due to large interindividual differences at inclusion, percentage variations from baseline were also calculated to describe the relative changes in time. Correlations between parameters were searched using regression model analysis. The best correlation, i.e. linear, logarithmic, exponential or power was determined by the highest value of the coefficient of correlation $r$. A $P$-value lower than 0.05 was considered significant.

\section{Results}

At entry in the study, the three groups of volunteers were characterized by similar values of the biometrological parameters (Table I). Pruritus and dandruff cleared in about 2-6 weeks as reported by the volunteers. None of the three treatments modified the mean hair density significantly (Table I). However, hair shedding during shampooing was significantly $(P<0.05)$ reduced after treatment with each of the three shampoos (Table I). The changes in anagen hair percentages between baseline values and those obtained after treatment showed a beneficial effect (Table I). A total of 15 (30\%) KTZ-treated subjects, $20(40 \%)$ PTO-treated subjects, and 16 (32\%) ZPTtreated subjects experienced an increase in the anagen hair percentages by more than $10 \%$ at the last evaluation. These differences were statistically significant $(P<0.05)$ within each group versus baseline, but the intergroup differences did not reach statistical significance. The scattergrams for this parameter in each test group point clearly above the bisectors and support the reproducibility of this observation in the whole population (Fig. 1a,b,c).

Changes in hair shaft diameter during treatment showed a significant $(P<0.05)$ increase in the KTZand PTO-treated groups (Table I). By contrast, the

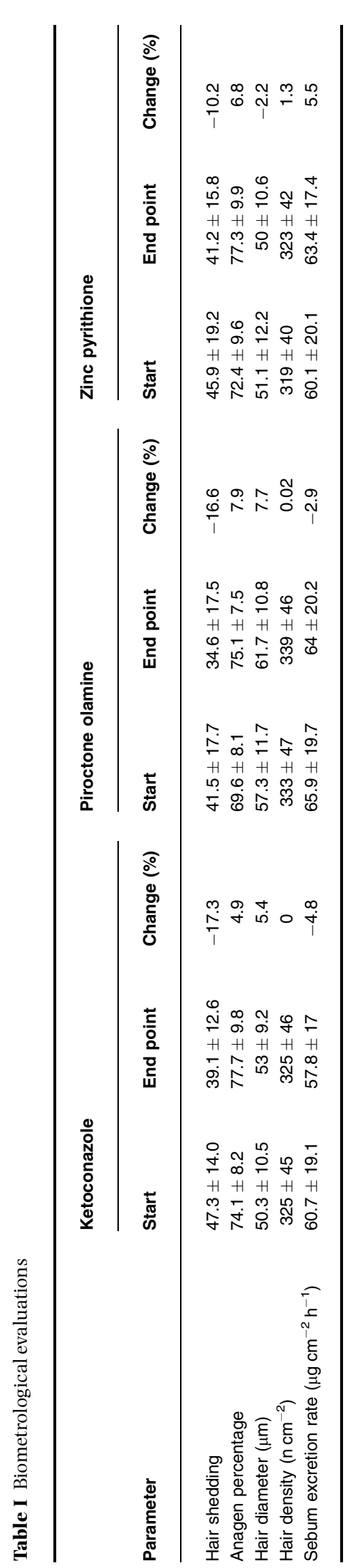



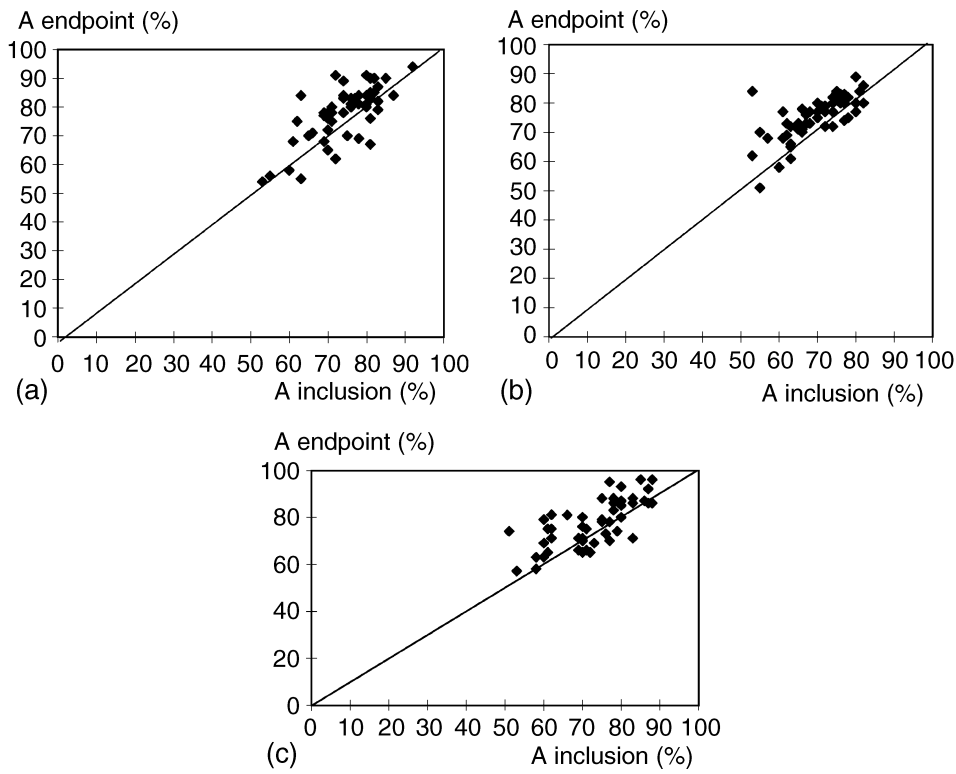

Figure 1 Scatterplot of the anagen hair percentages at entry and at completion of the study. (a) KTZ, (b) PTO, and (c) ZPT.

diameter was slightly decreased in the ZPT-treated group. The intergroup differences between each of the two former groups and the latter group were statistically significant $(P<0.05)$. The intragroup change at 6 months from baseline in the KTZ and PTO groups yielded a significant difference $(P<0.05)$. Fourteen $(28 \%)$ subjects in the KTZ group and 17 (34\%) in the PTO group had a mean hair diameter increase of more than $10 \%$ compared to baseline, versus only four of (8\%) ZPT users. Only 11 (22\%) KTZ users and six (12\%) PTO users showed a negative value for the hair diameter variation, versus 37 (74\%) ZPT-treated subjects. For the KTZ and PTO groups, the vast majority of the individual values were located above the bisector of the scattergram (Fig. 2a,b). By contrast, the individual data about the ZPT group exhibited an overall trend to be below the bisector (Fig. 2c).

The scattergrams for baseline SER versus the posttreatment values are presented in Fig. 3 (a,b,c). A trend in SER decrease was seen in the KTZ and PTO groups,
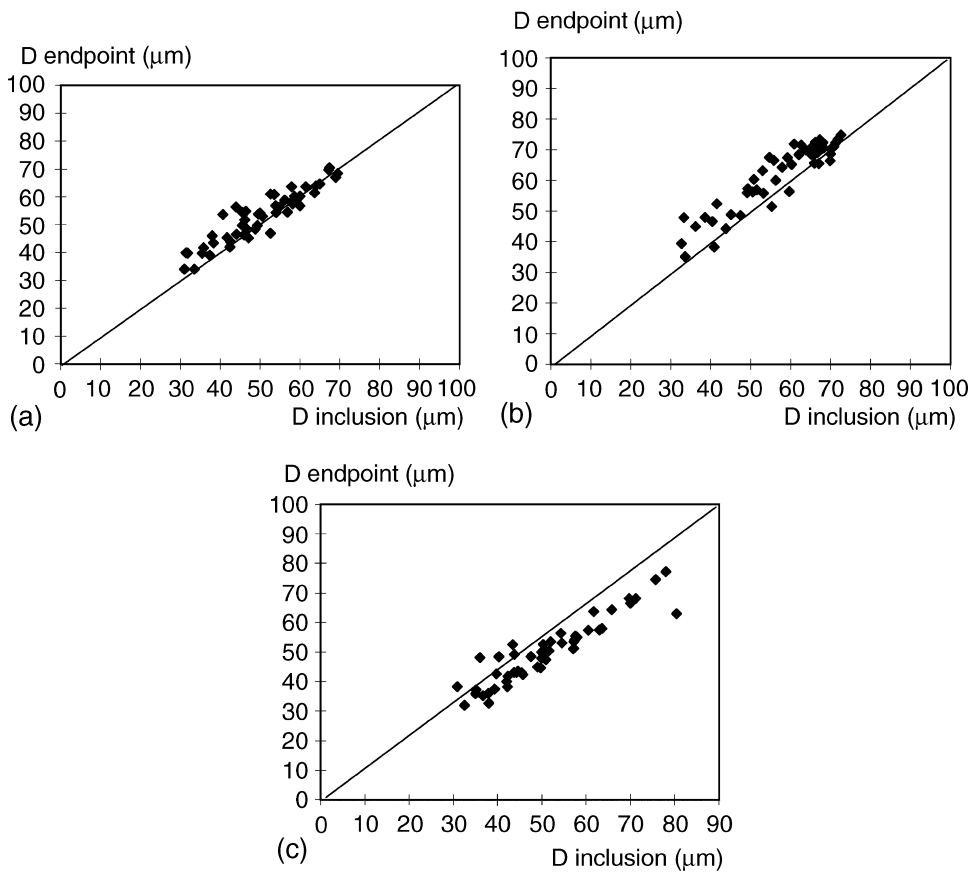

Figure 2 Scatterplot of the mean hair shaft diameter $(\mathrm{D}, \mu \mathrm{m})$ at entry and at completion of the study. (a) KTZ, (b) PTO, and (c) ZPT. 
Figure 3 Scatterplot of the sebum excretion rate (SER, $\mu \mathrm{g} \mathrm{cm}^{-2} \mathrm{~h}^{-1}$ ) at entry and at completion of the study. (a) KTZ, (b) PTO, and (c) ZPT.

whereas the ZPT group showed a statistically significant increase $(P<0.05)$ over that same period. These intergroup differences were highly significant between each of the KTZ and PTO groups, and the ZPT group $(P<0.001)$. The scattergrams showed the large majority of individual data pointed below the bisector for KTZ and PTO, and above the bisector for ZPT.

Correlations between SER, anagen hair proportions and hair shaft diameter were searched for independence from the nature of shampoo, since

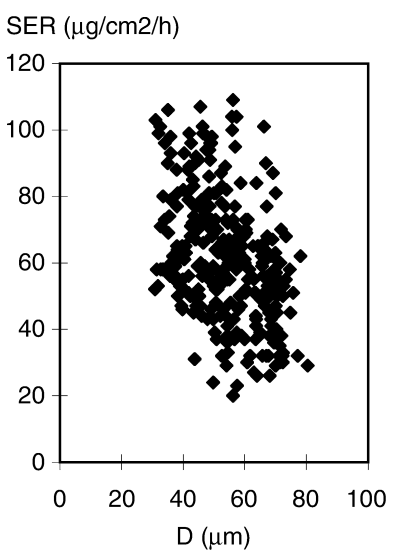

Figure 4 Relationship between the sebum excretion rate (SER, $\mu \mathrm{g} \mathrm{cm}^{-2} \mathrm{~h}^{-1}$ ) and hair shaft diameter (D, $\left.\mu \mathrm{m}\right)$. it addressed changes in biological parameters in relation to each other. When pooling all the data, a negative linear relationship $(r=-0.66, \quad P<0.01)$ was found showing that with increasing SER, the hair shaft diameter appeared to be thinner (Fig. 4). A trend in a positive correlation $(r=0.55)$ was yielded between the anagen hair proportion and the hair shaft diameter (Fig. 5). No correlation was found $(r=-0.11)$ between the sebum excretion rate and the anagen hair proportion (Fig. 6).

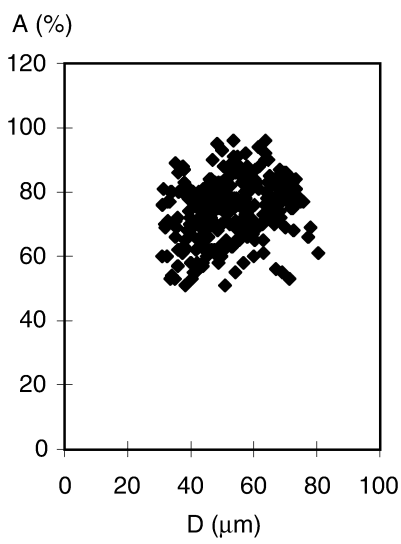

Figure 5 Relationship between the hair shaft diameter (D, $\mu \mathrm{m})$ and the proportion of hair in anagen phase (A, \%). 


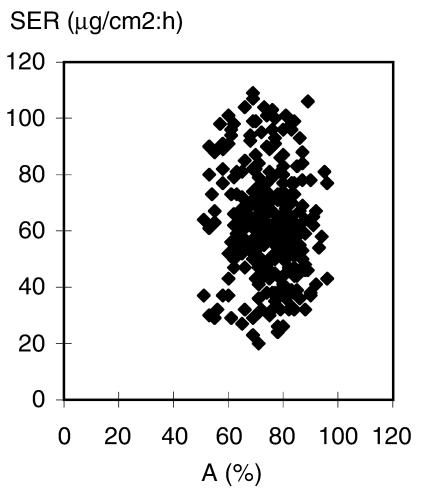

Figure 6 Relationship between the sebum excretion rate (SER, $\mu \mathrm{g} \mathrm{cm}^{-2} \mathrm{~h}^{-1}$ ) and the proportion of hair in anagen phase $(\mathrm{A}, \%)$.

\section{Discussion}

The link between dandruff and seborrhoeic dermatitis as two clinical manifestations of the same disease was reported more than a century ago. Despite some attempts to disprove this observation, data yielded during the last 15 years have confirmed the initial concept [21-36]. Nevertheless, it is surprising that only few researchers have tried to make conclusive links between this very common scalp problem and other scalp disorders that are regularly seen in the population.

Only sebaceous gland activity has routinely been mentioned in relation to seborrhoeic dermatitis. Some authors reported that sebaceous gland activity hardly increased in cases of dandruff and even contended that in cases of inflammatory seborrhoeic dermatitis or in seborrhoea itself, it was the sebum composition that was changed more than the amount in lipids. The fact that the presence of the lipophilic yeasts, Malassezia spp., has been associated with dandruff and seborrhoeic dermatitis is at least suggestive of an increased presence of sebum or Malassezia spp.-specific nutrients on the scalp. Sebum excretion can actually be increased in individuals with seborrhoeic dermatitis [30].

Links between increased hair shedding, alterations in the anagen/telogen ratio and hair shaft diameter on the one hand, and dandruff on the other hand have not been thoroughly documented. Dandruff may occur with androgenic alopecia and it may exaggerate hair loss. There are also some reports on thinning of the hair shaft, reduced percentage in anagen hair and development of telogen effluvium in conjunction with inflammatory disorders of the scalp $[1,30]$. However, it is clear from the limited num- ber of these references that the relationship between these different clinical phenomena has not been made routinely in the past.

The investigations done in the present trial, therefore, offer some new findings despite the fact that a bland shampoo was not used as control. Indeed, a bland shampoo was not considered in the present study because, in our experience, it is almost impossible to run a 6-month study using a placebo without having numerous protocol violations and drop-out. The data suggest that $1 \% \mathrm{KTZ}, 1 \%$ PTO and $1 \% \mathrm{ZPT}$ shampoos are capable of improving the anagen to telogen ratio by increasing the percentage of anagen hair on the scalp. The clinical correlate of this effect is a reduction in hair shedding during shampooing. It is worth noting that the reduction in hair shedding is supportive evidence for the increase in the percentage of anagen hair or for delayed teloptosis [4]. It should be stressed that a seasonal effect [2, 19] may be a confounding factor influencing hair shedding independently of the activity of the antifungal agents. However, other findings, which were observed with $1 \% \mathrm{KTZ}$ and $1 \%$ PTO, but not with $1 \%$ ZPT, cannot be explained by chronobiology alone. It deals with the trend in SER reduction on the scalp, which correlated with an increase in hair shaft diameter. One could argue that a 10\% increase in hair shaft diameter is of minor amplitude. However, assuming hair is a cylinder, its volume and weight are dependent on the square power of its diameter. Hence, the average $10 \%$ increase in diameter corresponds to a $20 \%$ increase in its volume $\left(1.1^{2}=1.21\right)$. Such a change likely implies a larger amount of hair cells associated or not with increased synthesis of keratins and other molecular compounds.

If anything, SER moderately went up in the ZPT group, and that correlated with a slight decrease in the hair shaft diameter. Although scalp seborrhoea apparently correlated well with the reduction in hair shaft diameter, this finding does not necessarily represents a causative relationship. Indeed, both parameters are largely under the influence of androgens [16]. In addition, sebocytes contain high amounts of $5 \alpha$-reductase and synthesize and release $5 \alpha$-dihydrotestosterone, which may influence the hair growth and size [38]. This mechanism might be operative and be in part responsible for the heterogeneity in the expression of follicule miniaturization typical for androgenic alopecia [39]. It is not excluded that hair care products that would beneficially affect the amount of sebum produced on the scalp might also produce thicker hair. 
The convergence between KTZ, PTO and ZPT for improving anagen percentage and daily hair shedding, and the divergence between products for scalp seborrhoea and hair shaft diameter, suggest that antidandruff shampoos may affect hair and scalp through different mechanisms despite the fact that they exert their effect on the Malassezia yeasts. The modulation of innate antimicrobial defenses such as defensins [40] by some of the topical products cannot be ruled out. The opposite effect of shampoos on sebum output at the skin surface argues for not being a seasonality effect.

\section{Conclusion}

The present study comparing 1\% KTZ, 1\% PTO and $1 \%$ ZPT shampoos has demonstrated that these products have some other benefits in addition to their reported antidandruff effect. The data show that these shampoos have a beneficial effect on the anagen/telogen ratio, by increasing the anagen hair percentage in subjects with dandruff. This results in a reduced hair shedding. In addition, the data show that $1 \% \mathrm{KTZ}$ and $1 \%$ PTO, but not $1 \% \mathrm{ZPT}$, produce a beneficial effect on scalp seborrhoea and hair shaft diameter. The reason for such opposite effect is unknown. Finally, the data show that scalp seborrhoea is inversely correlated with hair thickness. The virtue of such a finding is its simplicity. However, the results cannot be taken at face value. There may remain debate whether reducing sebum excess on the scalp may lead to thicker hair, and whether increasing scalp seborrhoea may be accompanied by a reduction in the hair shaft diameter.

\section{References}

1. Piérard-Franchimont, C. and Piérard, G.E. A propos du follicule pileux et du cycle pilaire: considérations récentes. Rev. Med. Liège 52, 671-674 (1997).

2. Courtois, M., Loussouarn, G., Hourseau, S. and Grollier, J.F. Periodicity in the growth and shedding of hair. Br. J. Dermatol. 134, 47-54 (1996).

3. Stenn, K.S. Growth of the hair follicle: a cycling and regenerating biological system. In: Molecular basis of epithelial appendage morphogenesis (C.M. Chuong, ed.), pp. 111-124. Landes Biosciences, Austin (1998).

4. Piérard-Franchimont, C. and Piérard, G.E. Teloptosis, a turning point in hair shedding biorythms. Dermatology 203, 115-117 (2001).

5. Stenn, K.S., Nixon, A.J., Jahoda, C.A.B., McKay, I.A. and Paus, R. What controls hair follicle cycling? Exp. Dermatol. 8, 229-236 (1999).
6. Van Steensel, M.A.M., Van Geel, M. and Seijjen, P.M. The molecular basis of hair growth. Eur. J. Dermatol. 11, 348-352 (2001).

7. Piérard, G.E. and de la Brassinne, M. Modulation of dermal cell activity during hair growth in the rat. J. Cutan. Pathol. 2, 35-41 (1975).

8. Paus, R., Mecklenburg, L. and Tobin, D.J. Active hair growth (anagen) is associated with angiogenesis. J. Invest. Dermatol. 114, 909-916 (2000).

9. Jaworsky, C., Kligman, A.M. and Murphy, G.F. Characterization of inflammatory infiltrates in male pattern alopecia: implication for pathogenesis. Br. J. Dermatol. 127, 239-246 (1992).

10. Paus, R., Böttge, J.A., Henz, B.M. and Maurer, M. Hair growth control by immunosuppression. Arch. Dermatol. Res. 288, 408-410 (1996).

11. Piérard, G.E., Piérard-Franchimont, C., Nikkels-Tassoudji, N., Nikkels, A.F. and Saint Léger, D. Improvement in the inflammatory aspect of androgenetic alopecia. A pilot study with an antimicrobial lotion. J. Dermatol. Treat. 7, 153-157 (1966).

12. Bohm, M. and Luger,T.A. The pilosebaceous unit is part of the skin immune system. Dermatology 196, 76-79 (1998).

13. Piérard-Franchimont, C., De Doncker, P., Wallace, R., Cauwenbergh, G. and Piérard, G.E. Ketoconazole shampoo: effect of long term use in androgenic alopecia. Dermatology 196, 474-488 (1998).

14. Christoph, T., Müller-Röver, S., Audring, H., et al. The human hair follicle immune system. cellular composition and immune privilege. Br. J. Dermatol. 142, 862-872 (2000).

15. Mahé, Y.F., Michelet, J.F., Billoni, N., et al. Androgenic alopecia and microinflammation. Int. J. Dermatol. 39, 576-584 (2000).

16. Randall, V.A., Hibberts, N.A., Thornton, M.J., et al. The hair follicle: a paradoxical androgen target organ. Horm. Res. 54, 243-250 (2000).

17. Randall, V.A., Hibberts, N.A., Thornton, M.J., et al. Do androgens influence hair growth by altering the paracrine factors secreted by dermal papilla cells? Eur. J. Dermatol. 11, 304-308 (2001)

18. Sawaya, M.E., Keane, R.W., Blume-Peytavi, U., et al. Androgen responsive genes as they affect hair growth. Eur. J. Dermatol. 11, 315-320 (2001).

19. Piérard-Franchimont, C. and Piérard, G.E. L'effluvium télogène actinique: une facette de la chronobiologie humaine. Int. J. Cosmet. Sci. 21, 15-21 (1999).

20. Rushton, D.H., Ramsey, I.D., Norris, M.J. and Gilkes, J.J.H. Natural progression of male pattern baldness in young men. Clin. Exp. Dermatol. 16, 188-192 (1991).

21. Shuster, S. The aetiology of dandruff and the mode of action of therapeutic agents. Br. J. Dermatol. 111, 232-242 (1984).

22. Shuster, S. Dandruff, seborrhoeic dermatitis and Pityrosporum ovale. Cosmet Toilet. 103, 87-91 (1988). 
23. McGrath, J. and Murphy, G.M. The control of seborrhoeic dermatitis and dandruff by antipityrosporal drugs. Drugs 41, 178-184 (1991).

24. Piérard-Franchimont, C., Arrese, J.E. and Piérard, G.E. Immunohistochemical aspects of the link between Malassezia ovalis and seborrhoeic dermatitis. J. Eur. Acad. Dermatol. 4, 14-19 (1995).

25. Hay, R.J. and Graham Brown, R.A.C. Dandruff and seborrhoeic dermatitis: causes and management. Clin. Exp. Dermatol. 22, 3-6 (1997).

26. Kesavan, S., Walters, C.E., Holland, K.T. and Ingham, E. The effects of Malassezia on pro-inflammatory cytokine production by human peripheral blood mononuclear cells in vitro. Med. Mycol. 36, 97-106 (1998).

27. Piérard-Franchimont, C., Arrese, J.E., Durupt, G., Ries, G., Cauwenbergh, G. and Piérard, G.E. Correlation between Malassezia spp load and dandruff severity. J. Mycol. Med. 8, 83-86 (1998).

28. Faergemann, J. Management of seborrhoeic dermatitis and pityriasis versicolor. Am. J. Clin. Dermatol. 1, 75-80 (2000).

29. Loden, M. and Wessman, C. The antidandruff efficacy of a shampoo containing piroctone olamine and salicylic acid in comparison to that of a zinc pyrithione shampoo. Int. J. Cosmet Sci. 22, 285-289 (2000).

30. Piérard-Franchimont, C., Hermanns, J.F., Degreef, H. and Piérard, G.E. Axioms to new insights into dandruff. Dermatology 200, 93-98 (2000).

31. Ford, G.P., Farr, P.M., Ive, F.A. and Shuster, S. The response of seborrhoeic dermatitis to ketoconazole. $\mathrm{Br}$. J. Dermatol. 111, 603-607 (1984).

32. Arrese, J, Piérard-Franchimont, C, De Doncker, P, Heremans, A, Cauwenbergh, G. and Piérard, G.E. Effect of ketoconazole medicated shampoos on squamometry and Malassezia ovalis load in pityriasis capitis. Cutis $\mathbf{5 8}$, 235-237 (1996).

33. Heng, M.C.Y., Henderson, C.L., Barker, D.C. and Haberfelde, G. Correlation of Pityrosporum ovale density with clinical severity of seborrhoeic dermatitis as assessed by a simplified technique. J. Am. Acad. Dermatol. 23, 8286 (1990).

34. Piérard, G.E., Arrese, J.E., Piérard-Franchimont, C. and De Doncker, P. Prolonged effect of antidandruff shampoos. Time to recurrence of Malassezia ovalis colonization of skin. Int. J. Cosmet. Sci. 19, 111-117 (1997).

35. Watanabe, S., Kano, R., Sato, H., Nakamura, Y. and Hasegawa, A. The effects of Malassezia yeasts on cytokine production by human keratinocytes. J. Invest. Dermatol. 116,769-773 (2001).

36. Piérard-Franchimont, C. and Piérard, G.E. Approche physiopathologique de la séborhée du cuir chevelu. Ann. Dermatol.Venereol. 115, 451-453 (1988).

37. Piérard, G.E., Piérard-Franchimont, C., Marks, R., Paye, M. and Rogiers, V. the EEMCO group. EEMCO guidance for the in vivo assessment of skin greasiness. Skin Pharmacol. Appl. Skin Physiol. 13, 372-389 (2000).

38. Zouboulis, C. Human skin: an independent peripheral endocrine organ. Horm. Res. 54, 230-242 (2000).

39. De Lacharrière, O., Deloche, C., Misciali, C., et al. Hair diameter diversity. A clinical sign reflecting the follicle miniaturization. Arch. Dermatol. 137, 641-646 (2001).

40. Chronnell, C.M., Ghali, R.S., Quinn, A.G., et al. Human beta defensin-1 and -2 expression in human pilosebaceous units: up-regulation in acne vulgaris lesions. J. Invest. Dermatol. 117,1120-1125 (2001). 